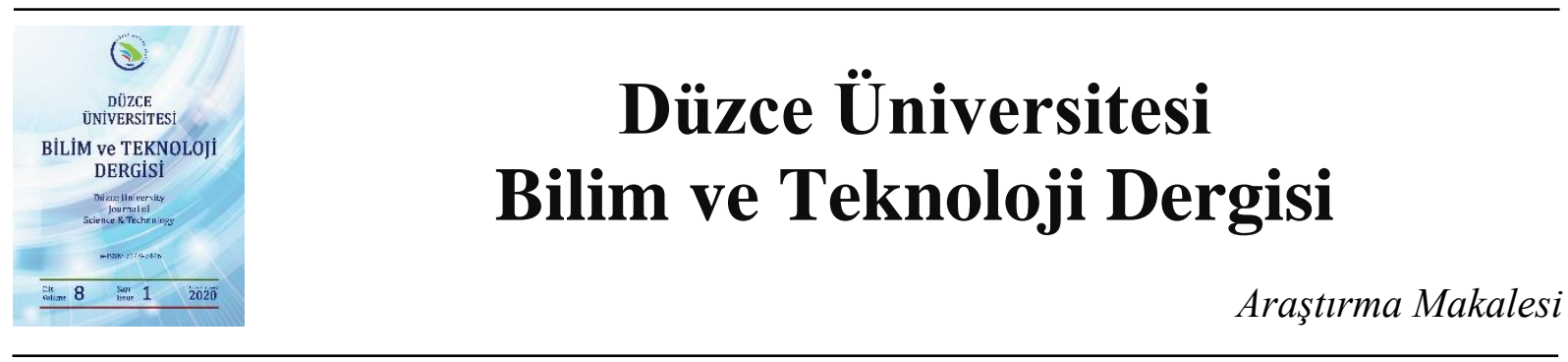

\section{Paralel Bağlı Karşıt Akışlı Ranque-Hilsch Vorteks Tüp Sisteminde Farklı Çalışma Akışkanı ve Nozul Malzemesi Kullanımının Performansa Etkisinin Deneysel İncelenmesi}

\author{
Volkan KIRMACI ${ }^{\text {a,* }}$ \\ ${ }^{a}$ Makine Mühendisliği Bölümü, Mühendislik Mimarlık ve Tasarım Fakültesi, Bartın Üniversitesi, Bartın, \\ TÜRKIYE \\ * Sorumlu yazarin e-posta adresi: volkankirmaci@bartin.edu.tr \\ DOI: $10.29130 /$ dubited.658242
}

\begin{abstract}
ÖZET
Bu çalışmada, iç çap 7 mm, gövde uzunluğu 100 mm ölçülerinde iki adet karşıt akışlı Ranque-Hilsch Vorteks Tüp (RHVT) paralel bağlanarak deneysel sistem oluşturulmuştur. Oluşturulan deneysel sistemdeki karşıt akışlı RHVT'lerde, Pirinç ve Polyamid Plastik malzemeden üretilmiş üç ve beş orfisli nozul kullanılmıştır. Oluşturulan deneysel sistemde giriș basıncı 2.0 ile 7.0 bar basınç değerleri arasında 1.0 bar aralıklarla basınçlı hava, oksijen ve azot kullanılarak RHVT den çıkan soğuk akışkan $\left(\mathrm{T}_{\text {soğ }}\right)$, sıcak akışkan $\left(\mathrm{T}_{\text {sıc }}\right)$ sıcaklığı ve RHVT performansı $\Delta T_{R H V T}\left(T_{\text {sic }}-T_{\text {soğ }}\right)$ cinsinden deneysel olarak etkileşimini incelenmiştir. Bu kapsamda, en iyi performansı sağlayan RHVT'nin optimum giriş basıncı, çalışma akışkanı, nozul malzemesi ve uygun orfis sayısı belirlenerek literatürdeki eksikliğin deneysel olarak incelenerek tamamlanması amaçlanmıştır. Deneysel sonuçlar

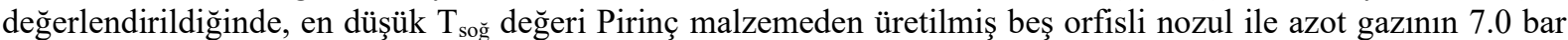
giriş basıncında $238.25 \mathrm{~K}$, en yüksek $\mathrm{T}_{\text {sic }}$ değerinin, Pirinç malzemeden üretilmiş beş orfisli nozul ile azot gazının 7.0 bar giriş basıncında $316.05 \mathrm{~K}$ ve en yüksek $\Delta \mathrm{T}_{\mathrm{RHVT}}$ değeri Pirinç malzemeden üretilmiş beş orfisli nozul ile azot gazının 7.0 bar giriş basıncında $77.8 \mathrm{~K}$ olduğu tespit edilmiştir.
\end{abstract}

Anahtar Kelimeler: Ranque-Hilsch Vorteks Tüp, Isttma, Soğutma

\section{Experimental Investigation of the Effect of Different Working Fluid and Nozzle Material on Performance in Parallel Connected Counterflow Ranque-Hilsch Vortex Tube System}

\begin{abstract}
In this study, an experimental system was formed by connecting two counter-flow Ranque-Hilsch Vortex Tubes (RHVT) having inner diameter of $7 \mathrm{~mm}$ and main tube length of $100 \mathrm{~mm}$. The parallel connected counter-flow RHVT experimental system were used to conduct tests with three and five orifice nozzles made of Brass and Polyamide Plastic. In this experimental system, inlet air pressure between 2.0 and 7.0 bar pressure values with 1.0 bar increments using compressed air, oxygen and nitrogen. The difference between the temperature of the cold fluid outlet $\left(T_{c}\right)$ and hot fluid $\left(T_{h}\right)$ outlet from RHVT and cooling-heating performance was investigated experimentally by evaluating $\Delta T_{\text {RHVT }}\left(T_{h}-T_{c}\right)$. In this context, it is aimed to determine the optimum inlet pressure, working fluid, nozzle material and appropriate nozzle number of RHVT, which provides the best performance, and to fill the gap in the literature by examining it experimentally. When the experimental results are evaluated, the lowest Tc value is $238.25 \mathrm{~K}$ at 7.0 bar inlet pressure of nitrogen gas with five nozzle number produced from Brass material, $316.05 \mathrm{~K}$ and the highest $\Delta \mathrm{T}_{\mathrm{RHVT}}$ value at 7.0 bar inlet pressure of nitrogen gas with five nozzle
\end{abstract}


number produced from Brass material. It has been determined that the nitrogen gas is $77.8 \mathrm{~K}$ at the inlet pressure of 7.0 with five nozzles made of brass.

Keywords: Ranque-Hilsch Vortex Tube, Heating, Cooling

\section{GİRIS}

Vorteks tüpler, 1931 yılında George Joseph Ranque tarafindan keşfedilmiş [1] ve 1947 yılında Rudoph Hilsch geliştirerek günümüzdeki kullanıldığı şekilde dizayn etmiştir [2,3]. Keşfi ve geliştirmesini geçekleştiren araştırmacılarından dolayı bu tüplere Ranque-Hilsch Vorteks Tüp (RHVT) olarak adlandırılmıştır [4]. RHVT'ler, sadece gaz halindeki basınçlı akışkanla çalışan, aynı anda soğutma ve 1sıtma yapabilen basit bir sistem olup, sıcak akışkan çıkış tarafındaki kontrol vanasından başka hiçbir hareketli parçası yoktur [5]. Boyutlarının küçük ve hafif olmaları, hareketli ve elektronik parçaların olmaması, gecikmesiz rejime ulaşmaları, kimyasal soğutkanlar gerektirmemeleri ve dolaysıyla ekolojik açıdan zararlı olmamaları gibi birçok özellikleri ile RHVT'ler günümüzde birçok soğutma ve ısıtma problemine çözüm olabilmektedirler [6-9]. Şekil 1'de karşıt akışlı RHVT'ün çalışma prensibi ve nozulun şekli gösterilmiştir.

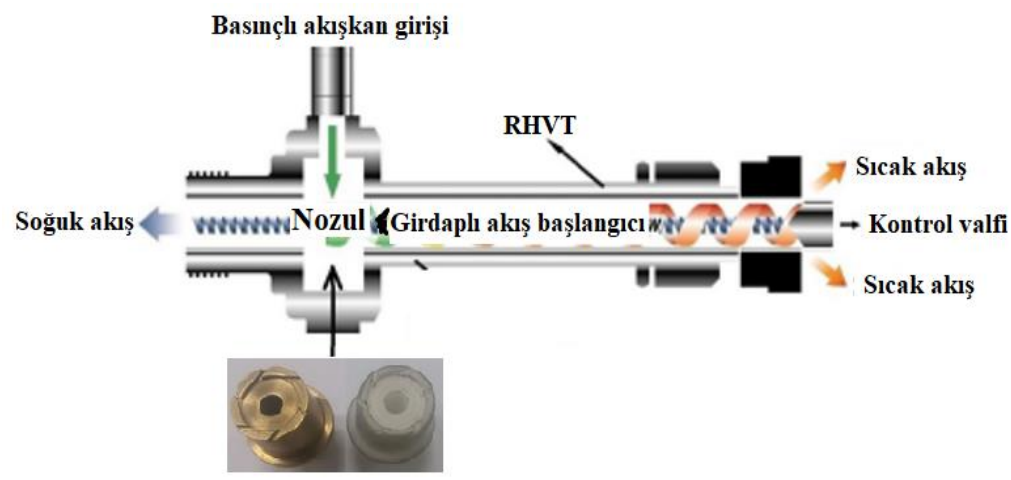

Şekil 1. Karşıt akışlı RHVT ve nozul yapısı [9]

RHVT'üne teğetsel olarak giren basınçlı gaz akışkan ile tüp içerisinde, vorteks tüpüne giren akışkandan daha sıcak olan ve daha soğuk olan iki farklı akış oluşur. RHVT girişinden giren basınçlı akışkanın nozuldan geçerek basıncı düşer, akışkan hızı ise artarak tüp içerisinde hareketine devam eder. Akışkan RHVT'nin silindirik yapısı ile yüksek açısal hızlarda dönmeye başlar. Akışkan merkezkaç kuvvetinden dolayı, tüp çeperine doğru genişlemeye başlar ve bu esnada merkezindeki akışkan ile RHVT çeperindeki akışkan arasında basınç farkı meydana gelir.

Meydana gelen basınç farkı ile akışkan radyal yönde orta noktaya doğru genişler. Orta noktadaki akışkanın açısal hızı $\left(\omega_{\text {soğ }}\right)$, açısal momentumun korunumu ilkesinden dolayı RHVT'nin çeperindeki akışkanın açısal hızından $\left(\omega_{\text {sıc }}\right)$ daha yüksektir. Bunun sonucunda, RHVT'de iki farklı hızda dönen iki farklı akış oluşur. Orta noktadaki akışkan daha yüksek hıza sahip olduğundan orta noktadaki akışkandan çeperdeki akışkana mekanik enerji transferi gerçekleşir. Mekanik enerjisi azalan tüp merkezindeki akış soğuk akıştır. RHVT çeperindeki sürtünmeden ve merkezdeki akışkandan gerçekleşen mekanik enerji transferinden dolayı çeperdeki akışkan sıcak akıştır. RHVT'lerde ile aynı anda soğuk ve sıcak akışkan meydana gelmesi, iki değişik açısal hızlarda dönen akışkan tarafından meydana gelen mekanik enerji transferi Şekil 2'de verilmiştir [10-14]. 


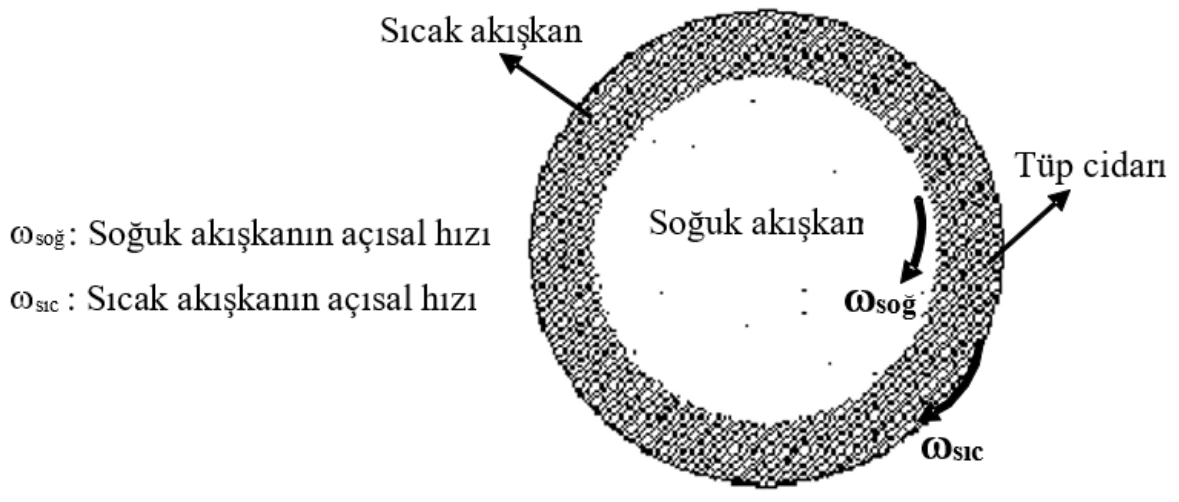

Şekil 2. RHVT gerçekleşen enerji transferi [3]

Dinçer vd. (2011), tamamladıkları deneysel çalışmada, dört orfisli nozullu, gövde uzunluğunun çapa oranı (L/D) 15 ve iç çapı 9 mm ebatlarındaki üç adet karşıt akışlı RHVT kullanmışlardır. Üç adet karşıt akışlı RHVT, tek ve iki adet RHVT birbirine sıcak kaskad tipi karşıt akışlı olarak bağlamışlar ve performanslarını deneysel olarak incelemişlerdir. Ayrıca, çalışmalarında ekserji analizlerini yapmışlardır. Tek RHVT'de çıkan soğuk akışkan sıcaklığı ile çıkan soğuk akışkan sıcaklığı arasındaki farkı $\left(\Delta \mathrm{T}_{\mathrm{H}}\right)$ değerinin $30.6{ }^{\circ} \mathrm{C}$ ve $73.5^{\circ} \mathrm{C}$ arasında ve sicak kaskad tipi RHVT'nin $\Delta \mathrm{T}_{\mathrm{H}}$ değerinin 52.35 ${ }^{\circ} \mathrm{C}$ ve $86.3^{\circ} \mathrm{C}$ arasında olduğu tespit etmişlerdir. Tamamladıkları deneysel çalışmanın sonucunda sıcak kaskad tipi karşıt akışlı RHVT'nin performansının tek karşıt akışlı RHVT'den daha yüksek olduğu belirtmişlerdir [15]. Günver (2018) tamamladığı yüksek lisans tez çalışmasında, $10 \mathrm{~cm}$ gövde uzunluğu, $7 \mathrm{~mm}$ iç çapı ebatlarında iki adet karşıt akışlı RHVT birbirine paralel bağlayarak deneysel sistemi oluşturmuştur. Oluşturduğu deneysel sistemde RHVT de 2, 4 ve 6 orfisli Polyamid, Alüminyum ve Pirinç malzemesinde nozullara $150 \mathrm{kPa}$ ile $550 \mathrm{kPa}$ basınç değerinde arasında $50 \mathrm{kPa}$ aralıklarla hava kullanarak enerji ayrışma olayını incelenmiştir [16]. Li vd. (2019) yaptıkları çalışmada, vorteks tüpünün soğuk akış oranı parametresinin, tüp içerisindeki üç boyuttaki hızın, statik basıncın ve toplam sıcaklık dağılımının üzerindeki etkisi incelenmiştir. Dört farklı soğuk akış oranı kullanılarak yapılan çalışmada, teğetsel hız Burgers vorteks formunda kabul edilmiş olup çalışma sonucunda bir ters akış sınırı tespit edilmiştir. Ayrıca yeni bir statik sıcaklık dağılımı önerilmiştir [17]. Khait vd. (2019) yaptıkları çalışmada, çift devreli bir vorteks tüpü sisteminde yerel entopi üretiminin değişimini incelemek amacıyla sayısal bir çalışma gerçekleştirmişlerdir. Entropi üretimi ve tersinmezlikler kullanılarak bir optimizasyon çalışması yapılmıştır. Nozula yakın alanlarda türbülans dağılımı nedeniyle tersinmezliklerin olduğu tespit edilmiştir. Vorteks tüp çapı, nozul geometrisi ve ikincil akışın türbülans derecesi optimizasyonu etkileyen parametreler olarak bildirilmiştir [18]. Kırmacı vd. (2018), tamamladıkları deneysel çalışmada, gövde uzunluğu $10 \mathrm{~cm}$, iç çapı $7 \mathrm{~mm}$ ebatlarındaki iki adet karşıt akışlı RHVT'ler paralel ve seri bağlamıştır. RHVT'de altı orfisli Alüminyum, Pirinç ve Polyamid Plastik malzemeli nozullar kullanmıştır. RHVT'de giriş basıncı olarak 2.0 bar ile 6.0 bar değerine arasında 0.5 bar aralıklarla hava kullanılarak soğutma ve 1sıtma sıcaklık performansları incelenmiştir. Deneyler sonucunda, RHVT'den çıkan en düşük soğuk akışkan sıcaklığ $1\left(\mathrm{~T}_{\text {soğ }}\right) 6.0$ bar giriş basıncında paralel bağlı RHVT'de alüminyum malzemedeki nozulda $-19.6{ }^{\circ} \mathrm{C}$, RHVT'de çıkan en yüksek sıcak akışkan sıcaklığ $1\left(\mathrm{~T}_{\mathrm{sIc}}\right)$ ise 6.0 bar giriş basıncında Paralel bağlı RHVT'de pirinç malzemedeki nozulda $41.6^{\circ} \mathrm{C}$ olduğunu ölçmüştür [14].

Bu çalışmada, gövde uzunluğu $100 \mathrm{~mm}$, iç çapı $7 \mathrm{~mm}$ olan iki adet karşıt akışlı RHVT'ler birbirine paralel bağlanarak deneysel sistem oluşturulmuştur. RHVT'lerde Polyamid Plastik ve Pirinç malzemeden üretilmiş üç ve beş orfisli nozullar kullanılmıştır. RHVT giriş basınc1 2.0 bar ile 7.0 bar değeri arasında, 1.0 bar aralıklarla değiştirilen hava, oksijen ve azot kullanılmıştır. Paralel bağlamış RHVT'lerden çıkan soğuk akışkan sıcaklığı $\left(\mathrm{T}_{\text {soğ }}\right)$ ile çıkan sıcak akışkan sıcaklığ $\left(\mathrm{T}_{\text {sic }}\right)$ sıcaklığ1 ölçülmüş ve performansı $\Delta \mathrm{T}_{\mathrm{RHVT}}\left(\mathrm{T}_{\mathrm{sic}}-\mathrm{T}_{\text {soğ }}\right)$ cinsinden deneysel olarak incelenmiştir. Bu kapsamda, en iyi performansı sağlayan RHVT'nin optimum giriş basıncı, çalışma akışkanı, nozul malzemesi ve uygun orfis sayısı belirlenerek literatürdeki eksikliğin deneysel olarak incelenerek tamamlanması amaçlanmıştır. 


\section{MATERYAL VE METOT}

Çalışmada, $7 \mathrm{~mm}$ iç çapı ve gövde uzunluğu $10 \mathrm{~cm}$ ölçülerindeki iki adet karşıt akışlı RHVT birbirine paralel bağlanmış ve eni $100 \mathrm{~cm}$, boyu $50 \mathrm{~cm}$, kalınlığ $2 \mathrm{~mm}$ olan metal levha üzerine Şekil 3'teki gibi yatay konumda sabitlenmiştir. RHVT kullanılan Polyamid Plastik ve Pirinç malzemelerinden üretilmiş üç ve beş orfisli nozullar kullanılmıştır. Deney sistemine giren basınçlı akışkanın basıncını ölçmek için \%1 hassasiyetinde manometre bağlanmıştır. Paralel bağlı oluşturulan RHVT sisteminden çıkan soğuk ve akışkan sıcaklı̆̆ını, basıncı ve kütlesel debisinin ölçümü için \%3 toleransa sahip Trust Science Innovation marka iki adet debimetre, sisteminin çıkışlarına bağlanmıştır. Ayrıca, paralel bağlanan RHVT çıkan soğuk ve sıcak akışın sıcaklıklarının ölçümü için $\pm 1{ }^{\circ} \mathrm{C}$ toleransında olan TFA marka iki adet dijital termometre kullanılmıştır. Kullanılan dijital termometre sisteminin sıcak ve soğuk çıkış bağlantı ucundan $10 \mathrm{~mm}$ ilerisine bağlanmıştır. Sistemde basınçlı havayı sağlamak için $20 \mathrm{~kW}$ 'lik kompresör kullanılmıştır. Hava kompresörü ile deneylerin başlangıç basıncı olan 2.0 bar basınç sağlanarak, RHVT soğuk ve sıcak çıkışta bulunan ölçüm değerleri sabitlenene kadar, kompresörden hava gönderilerek deney tamamlanmıştır. Bu işlemde sonra sırasıyla 2.0 ile 7.0 bar basınçlı hava ile malzemesi Pirinç ve Polyamid Plastik olan üç ve beş orfisli nozullarda deneyler yapılmış̧ır. Deneysel sistemde 2.0 ile 7.0 bar arasındaki basınçlı hava ile ilgili olan deneyler bitirildikten sonra hava kompresör bağlantısı çıkarılarak, yerine sırasıyla Oksijen ve Azot gazının muhafaza edildiği tüpler bağlanmış ve 2.0 ile 7.0 bar basınç değeri arasındaki deneysel işlemler hava deneylerinde yapılan işlemlerin aynısı yapılarak deneyler tamamlanmıştır. Bu çalışmada yapılan deneyler $21^{\circ} \mathrm{C}^{\prime}$ lik bir ortam sıcaklığ 1 yapılmıştır. Çalışmada elde edilen sonuçların doğruluğunun sağlanması amacıyla bir deney üç kez yapılmış ve ölçülen değerlerin ortalaması kullanılmıştır.

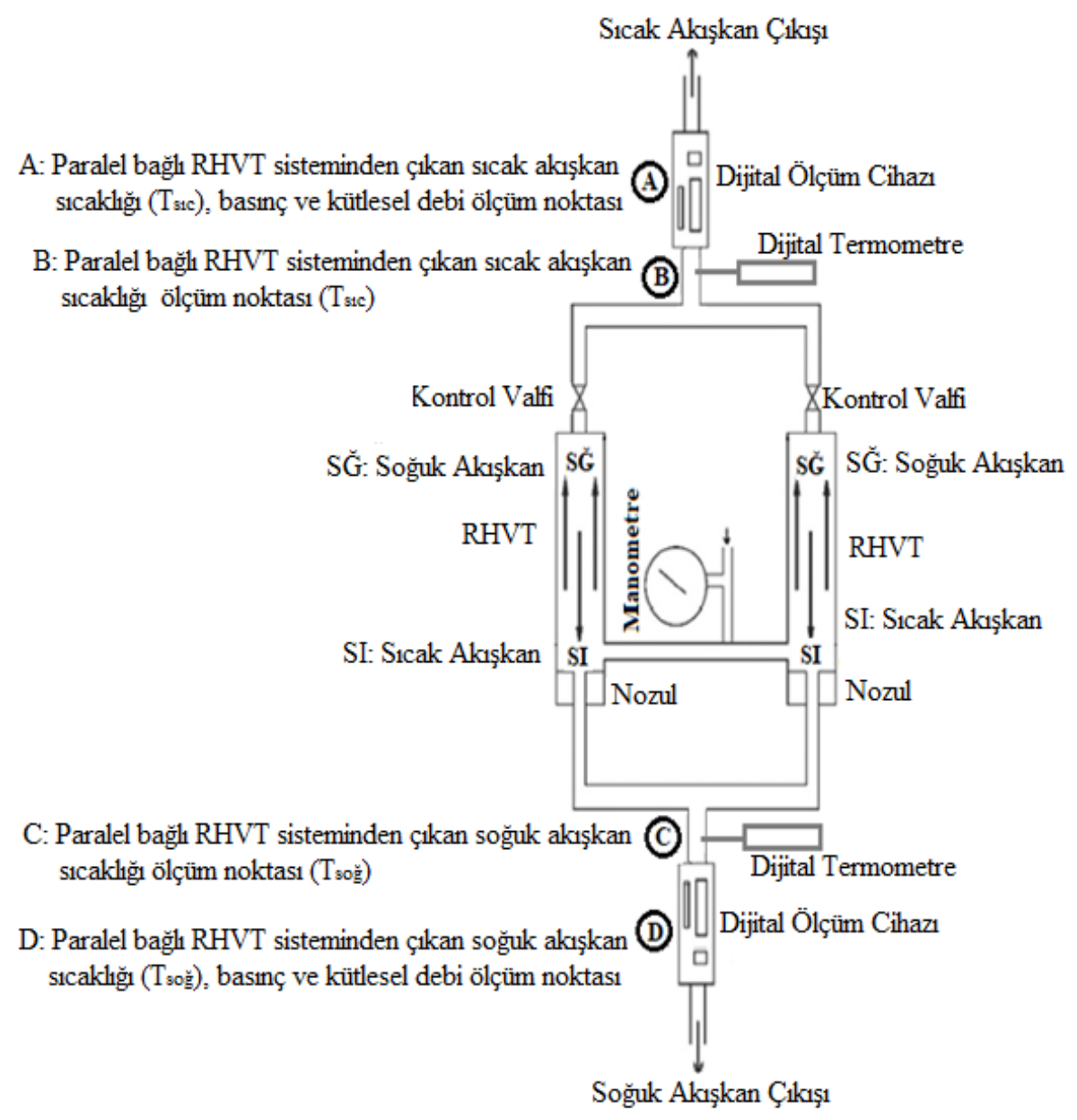

Şekil 3. Paralel Bağlı Karşıt Akışlı RHVT deneysel sistem şeması 


\section{BULGULAR VE TARTISMA}

Bu çalışmada, oda sıcaklığında ve yüksek basınçtaki gazdan giriş sıcaklığına göre daha sıcak ve daha soğuk iki farklı akım elde etmek için kullanılan RHVT'lerin Termodinamik analizi yapılmıştır. Çözümü esas alınan sistemin genel görünüşü Şekil 4'te verilmiştir.

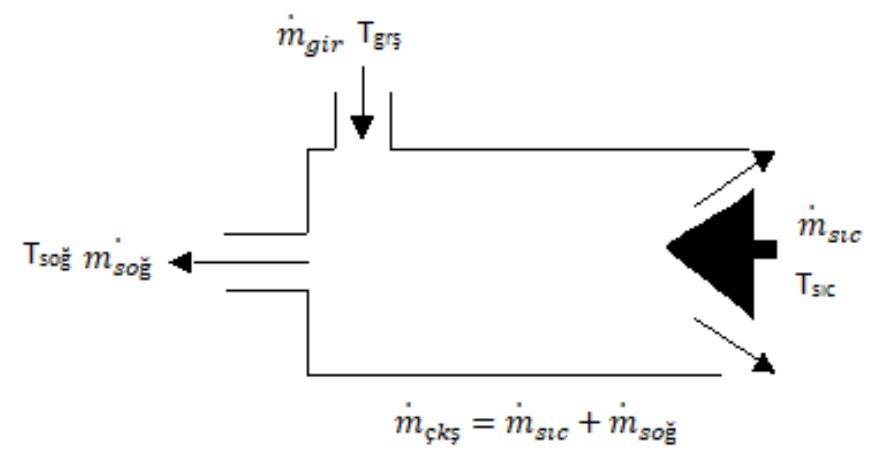

Şekil 4. Paralel Băğl Karşıt Akışlı RHVT deneysel sistem şeması

Sürekli akışlı sürekli açık sistemde bir giriş, bir çıkışlı için kütlenin korunumu Eşt. 1'de verilmiştir. Buna göre;

$\sum \dot{m}_{g i r}=\sum \dot{m}_{c ̧ s}$

$\dot{m}_{\text {gir }}$ : Sistem girişteki akışın kütlesel debisi, $\mathrm{kgs}^{-1}$

$\dot{m}_{c ̧ k s ̧}$ : Sistem çıkışındaki akışın kütlesel debisi, kgs $^{-1}$

şeklinde yazılabilir.

Eşt. 1'deki $\dot{m}_{c ̧ k s ̧}$ RHVT için Eşt. 2 şeklinde yazılabilir.

$\dot{m}_{c ̧ k s ̧}=\dot{m}_{s l c}+\dot{m}_{s o \breve{g}}$

$m_{S I C} \quad:$ RHVT'den çıkan sıcak akışın kütlesel debisi, $\mathrm{kgs}^{-1}$

$m_{s o g ̆}:$ RHVT'den çıkan soğuk akışın kütlesel debisidir, $\mathrm{kgs}^{-1}$.

RHVT'lerde girişteki akış sıcaklığı ( $\left.\mathrm{T}_{\text {grş }}\right)$ ile çıkan sıcak akış sıcaklık $\left(\mathrm{T}_{\text {sıc }}\right)$ fark, sıcak akış sıcaklık farkı $\left(\Delta \mathrm{T}_{\text {sıc }}\right)$ olarak tanımlanır ve Eşt. 3 'de verilmiştir.

$\Delta \mathrm{T}_{\mathrm{sic}}=\mathrm{T}_{\mathrm{sic}}-\mathrm{T}_{\mathrm{grss}}$

RHVT'lerde girişteki akış sıcaklığ 1 ( $\left.T_{\text {grş }}\right)$ ile çıkan soğuk akış sıcaklık $\left(T_{\text {soğ }}\right)$ farkı, soğuk akış sıcaklık farkı $\left(\Delta \mathrm{T}_{\text {soğ }}\right)$ olarak tanımlanır ve Eşt. 4'de verilmiştir [19-21].

$\Delta \mathrm{T}_{\mathrm{soğ}}=\mathrm{T}_{\mathrm{grş}}-\mathrm{T}_{\mathrm{soğ}}$

Eşt. 4 ve Eşt. 5 birleştirilip sadeleştirildiğinde, sıcak akışın sıcaklığı ve soğuk akışın sıcaklığı arasındaki fark $\Delta \mathrm{T}_{\mathrm{RHVT}} \mathrm{RHVT}$ performansı olarak Eşt. 5'de verilmiştir [22-26].

$\Delta \mathrm{T}_{\mathrm{RHVT}}=\mathrm{T}_{\mathrm{sic}}-\mathrm{T}_{\mathrm{soğ}}$ 
Vorteks tüpü performansını etkileyen en önemli faktörler akışkan giriş basıncı, nozul orfis sayısı, nozul malzemesi ve kullanılan akışkandır. Eşt. 5'de verilen, toplam sıcaklık farkı olarak da bilinen $\Delta \mathrm{T}_{\mathrm{RHVT}}$ parametresi RHVT gerçekleşen sıcaklık ayrılmasının ölçüsü olup vorteks akışının seviyesini belirler.

Paralel bağlanan iki adet karşıt akışlı RHVT'lerde Polyamid Plastik ve Pirinç malzemeden üretilmiş üç ve beş orfissli nozul, basınçlı akışkan olarak hava, oksijen ve azot kullanarak giriş basıncı 2.0 bar'dan başlayarak 7.0 bar'a kadar 1.0 bar aralıklarla arttırılarak sıcak akışkan çıkış ucunda ölçülen sıcaklık $\left(\mathrm{T}_{\mathrm{sic}}\right)$ değerlerinin değişimi sırasıyla Şekil 5-6-7'de verilmiştir.

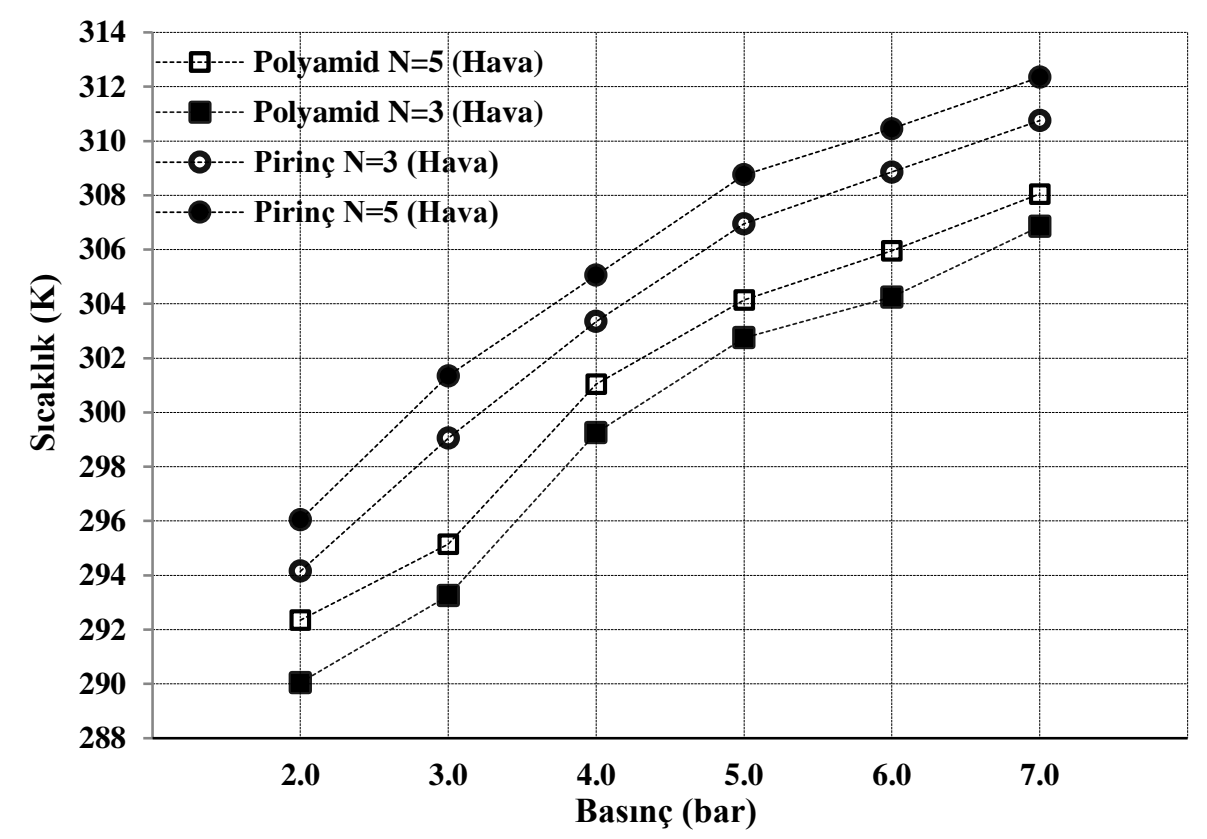

Şekil 5. Hava gazının çıkan sıcak akışkan sıcaklığının giriş̧ basıncına göre değişim grafiği

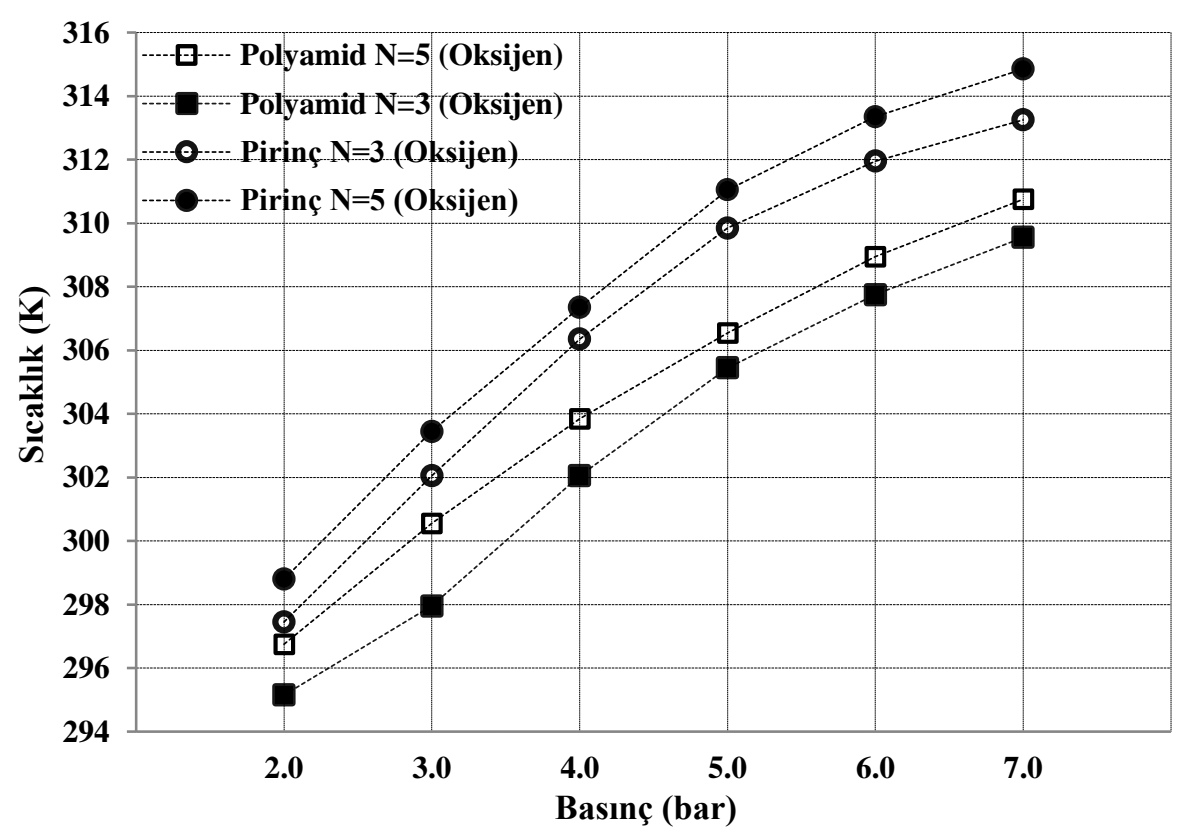

Şekil 6. Oksijen gazının çıkan sıcak akışkan sıcaklı̆̆ının giriş basıncına göre değişim grafiği 


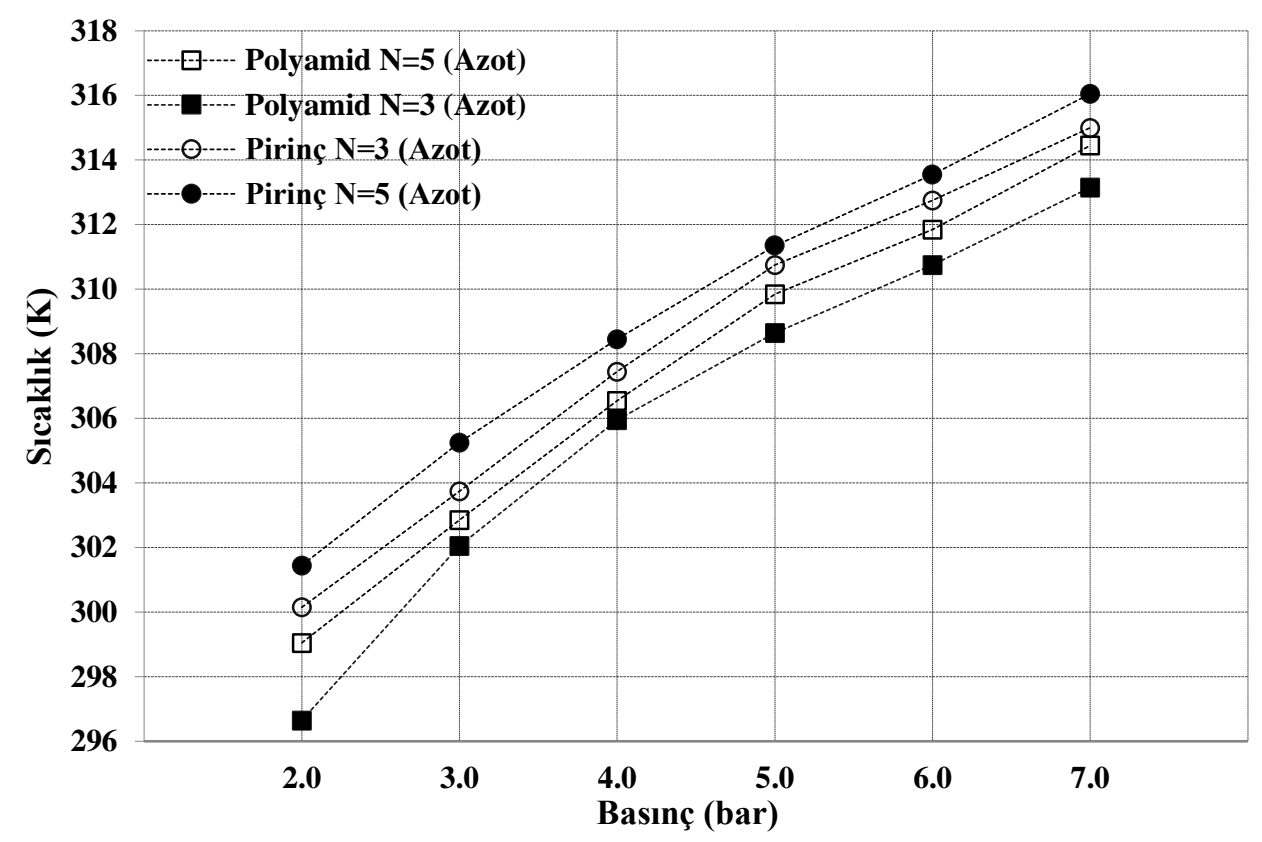

Şekil 7. Azot gazının çıkan sıcak akışkan sıcaklı̆̆ının giriş basıncına göre değişim grafiği

Şekil 5-6-7 incelendiğinde, maksimum $\mathrm{T}_{\text {sic }}$ değerinin, Pirinç malzemeden üretilmiş beş orfisli nozul ile azot gazının 7.0 bar giriş basıncında $316.05 \mathrm{~K}$ olduğu, minimum $\mathrm{T}_{\text {stc }}$ değerinin ise Polyamid Plastik malzemeden üretilmiş üç orfisli nozul ile havanın 2.0 bar giriş basıncında $290.05 \mathrm{~K}$ olduğu belirlenmiştir. Yapılan deneylerde, Pirinç malzemeden üretilmiş beş orfisli nozulda 7.0 bar giriş basınçlı hava ve oksijen gazlarında, $\mathrm{T}_{\text {stc }}$ değerleri sırasıyla $312.35 \mathrm{~K}, 314.85 \mathrm{~K}$ olduğu tespit edilmiştir. Öte yandan polyamid plastik malzemeden üretilmiş üç orfisli nozulda, 2.0 bar basınçlı oksijen ve azot gazı ile elde edilen sonuçlara göre, $\mathrm{T}_{\mathrm{sic}}$ değerleri sırasıyla $295.15 \mathrm{~K}, 296.65 \mathrm{~K}$ 'dir (Şekil 6-7).

Paralel bağlanan iki adet karşıt akışlı RHVT'lerde kullanılan orfis nozul sayısı, nozul malzemesi ve akışkan tipine göre soğuk akışkan çıkış ucunda ölçülen sıcaklık $\left(T_{\text {soğ }}\right)$ değerlerinin değişimi sırasıyla Şekil 8-9-10 da verilmiştir.

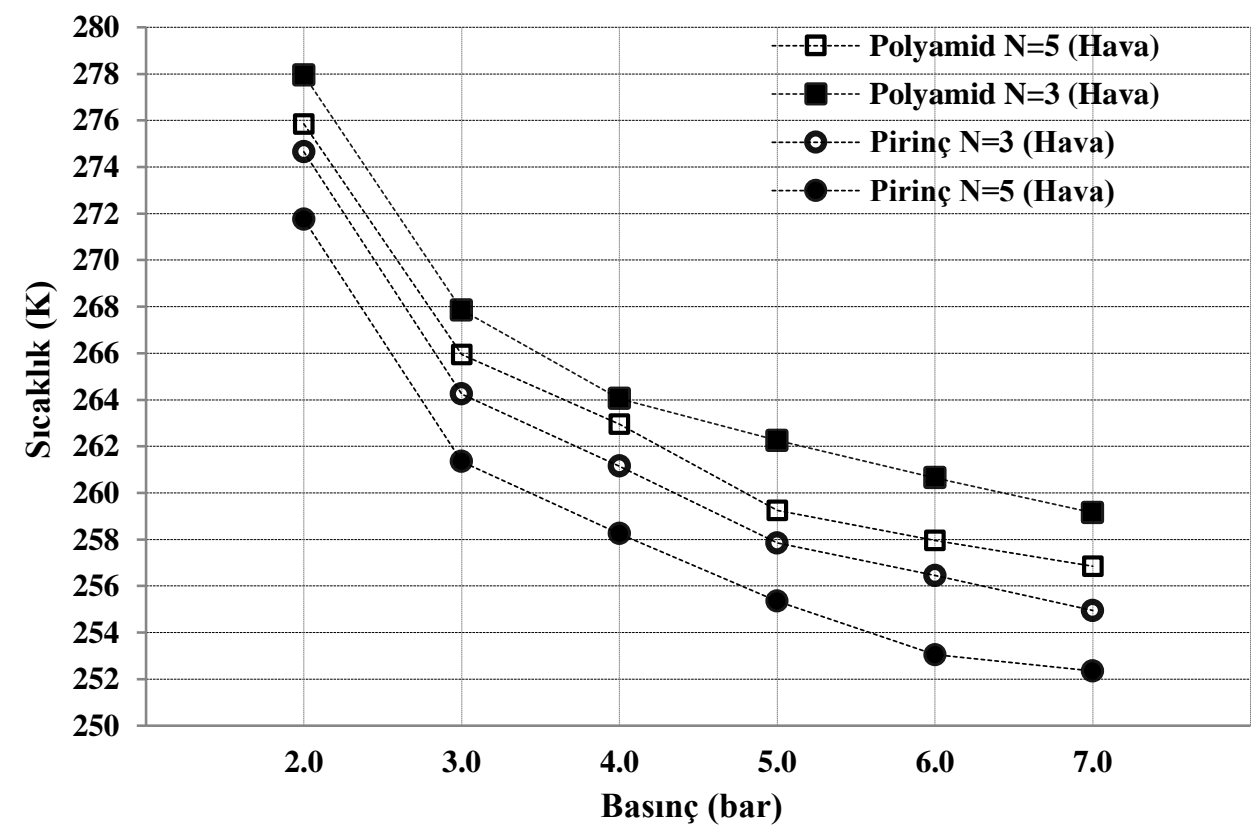

Şekil 8. Hava gazının çıkan soğuk akışkan sıcaklığının giriş basıncına göre değişim grafiği 


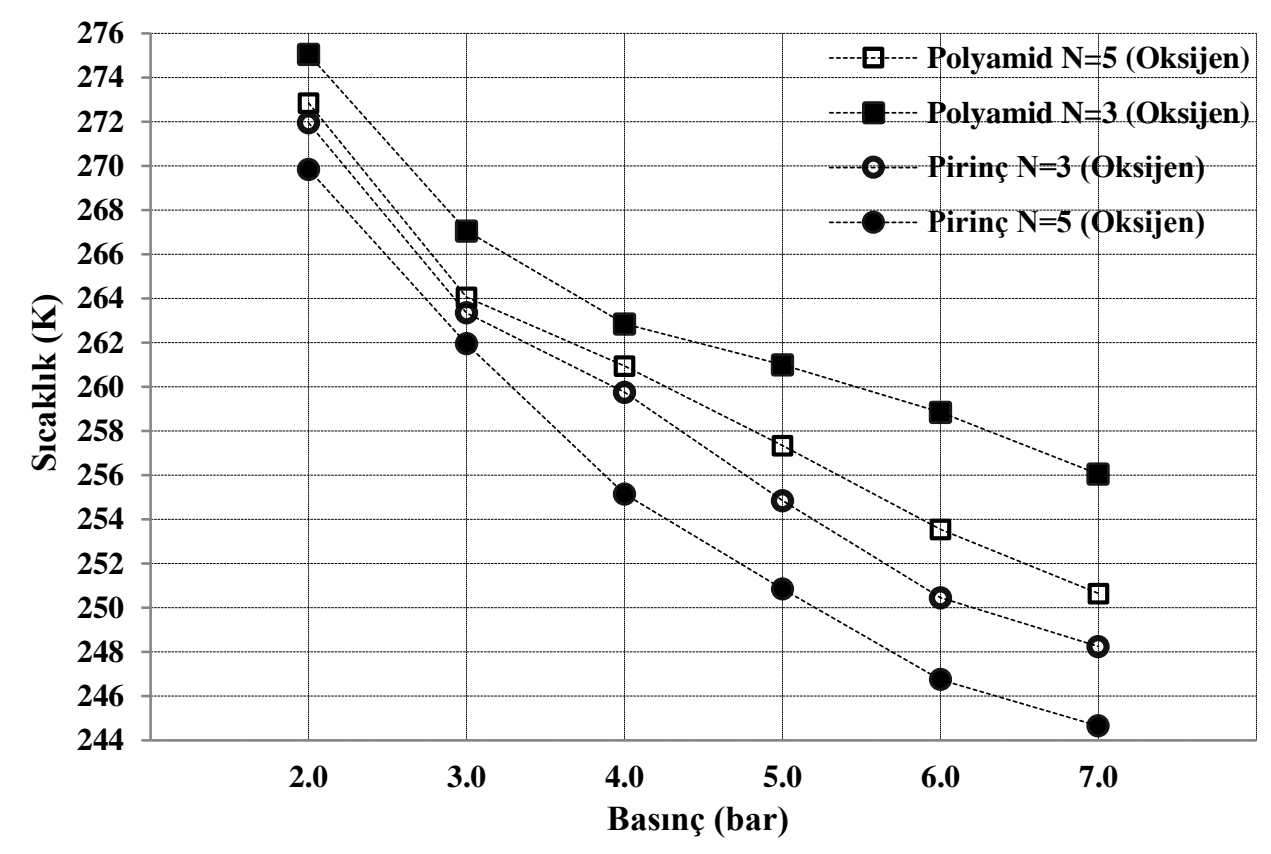

Şekil 9. Oksijen gazının çıkan soğuk akışkan sıcaklığının giriş basıncına göre değişim grafiği

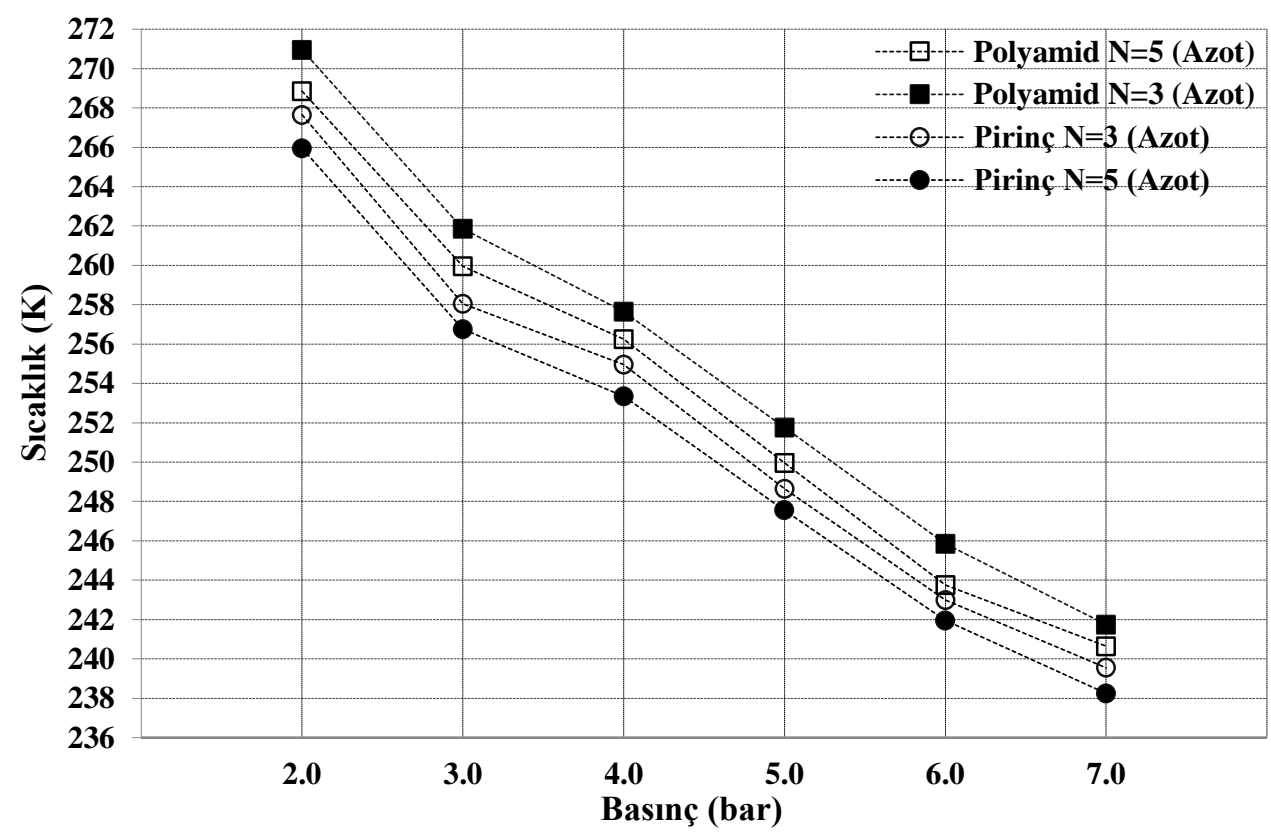

Şekil 10. Azot gazının çıkan soğuk akışkan sıcaklı̆̆ının giriş basıncına göre değişim grafiği

Şekil 8-9-10 karşılaştırıldığında, minimum $\mathrm{T}_{\text {soğ }}$ değeri Pirinç malzemeden üretilmiş beş orfissli nozul ile

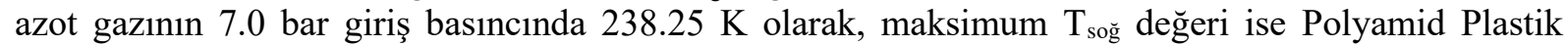
malzemeden üretilmiş üç orfisli nozul ile 2.0 bar basınçlı hava kullanıldığında $277.95 \mathrm{~K}$ olduğu görülmüştür. Pirinç malzemeden üretilmiş beş orfisli nozulda hava ve oksijen gazında 7.0 bar giriş basıncında, $\mathrm{T}_{\text {soğ }}$ değerlerinin sırasıyla $252.35 \mathrm{~K}, 244.65 \mathrm{~K}$ olduğu (Şekil 8-9), Polyamid Plastik malzemeden üretilmiş üç orfisli nozulda oksijen ve azot gazında giriş basıncında 2.0 bar giriş basıncında

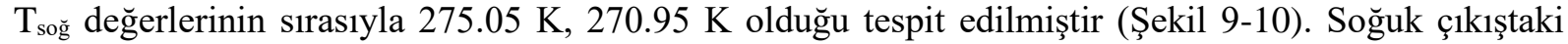
sıcaklığın düşük değerlerde olması soğutma amacı için istenen bir durumdur. Vorteks tüpündeki akış fiziksel olarak incelendiğinde, sıcaklık ayrılması ne kadar yüksek seviyelerde olursa, sıcak çıkış tarafı 1sınırken, soğuk çıkış tarafı ise oldukça soğumaktadır. 
Şekil 11-12-13'te sırasıyla hava, oksijen ve azot gazlarının paralel bağlı RHVT sisteminde performans parametresi olan ve aynı zamanda toplam sıcaklık farkı olarak adlandırılan $\Delta \mathrm{T}_{\mathrm{RHVT}}$ değerlerinin vorteks tüpü akışkanı giriş basıncına göre değişimi verilmiştir.

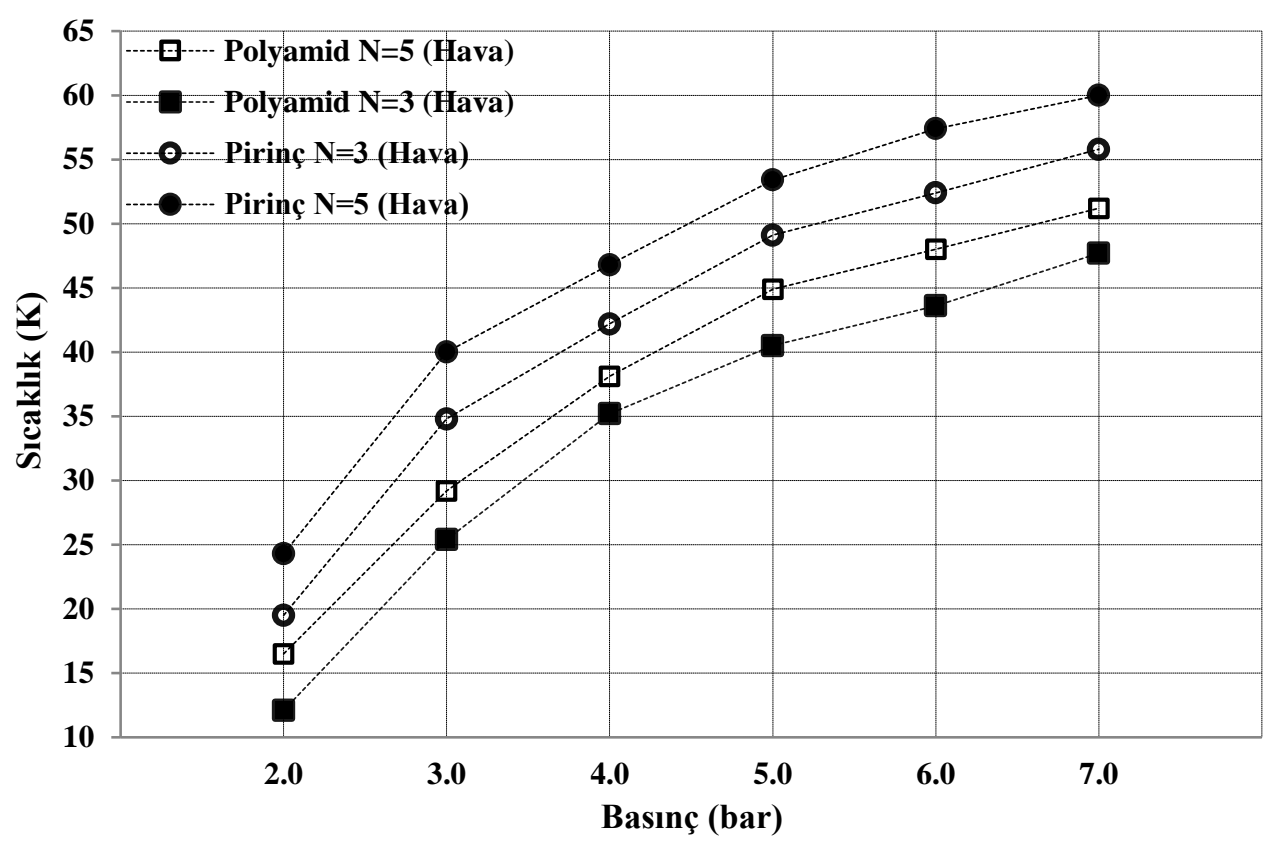

Şekil 11. Hava gazının $\Delta T_{R H V T}$ 'nın giriş basıncına göre değişim grafiği

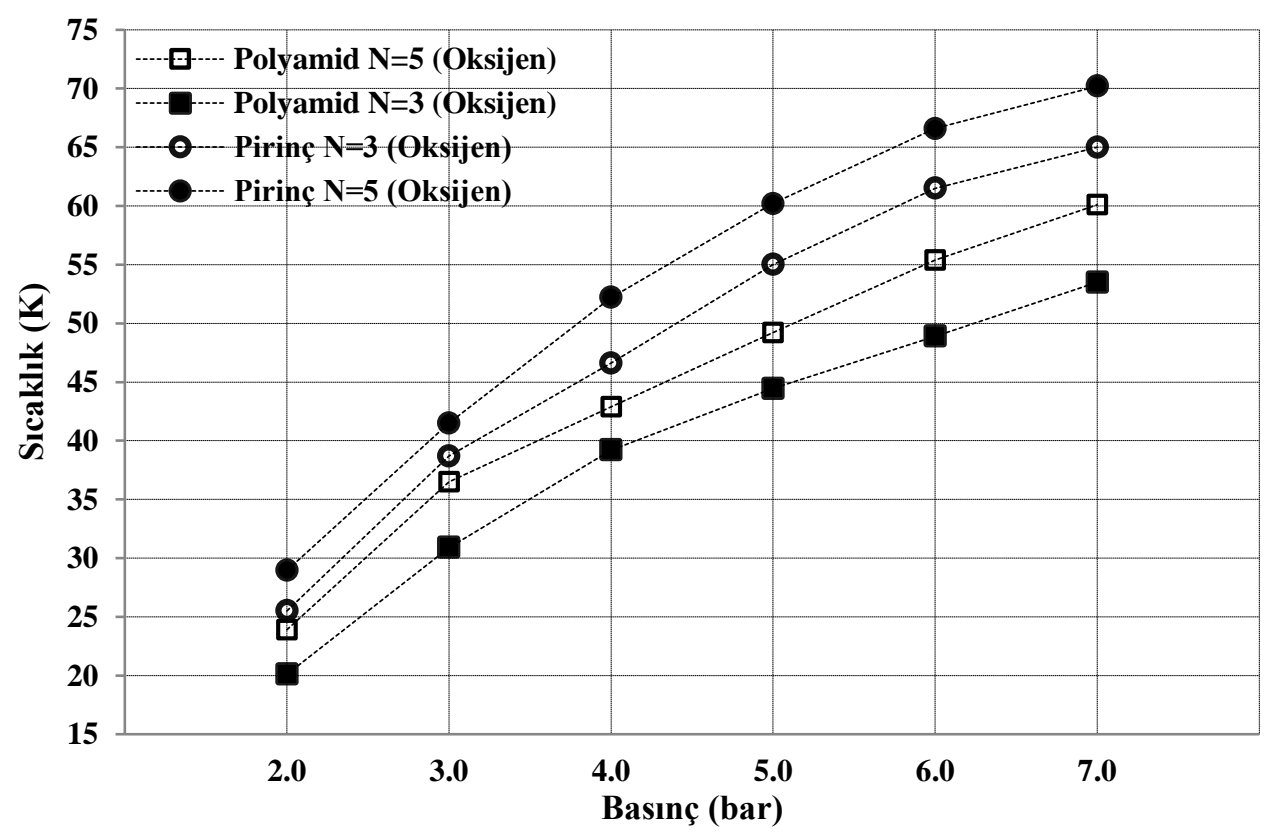

Şekil 12. Oksijen gazının $\Delta T_{R H V T}$ 'nın giriş basıncına göre değişim grafiği 


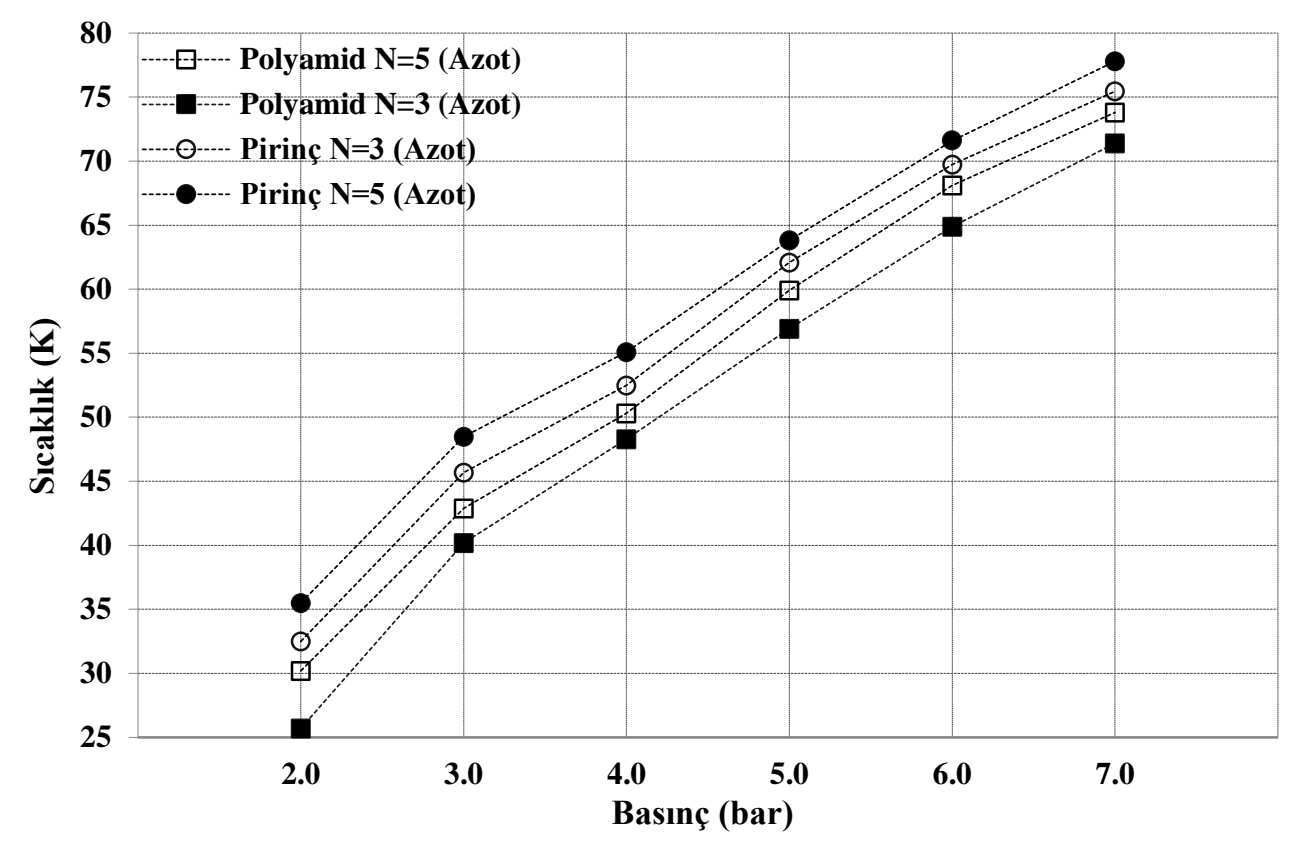

Şekil 13. Azot gazının $\Delta T_{R H V T}$ 'nin giriş basıncına göre değişim grafiği

Şekil 11, 12, 13 incelendiğinde, maksimum $\Delta \mathrm{T}_{\mathrm{RHVT}}$ değeri Pirinç malzemeden üretilmiş beş orfisli nozul ile azot gazının 7.0 bar giriş basıncında $77.8 \mathrm{~K}$ olarak, minimum $\Delta \mathrm{T}_{\mathrm{RHVT}}$ değeri ise Polyamid Plastik malzemeden üretilmiş üç orfisli nozul ile 2.0 bar basınçlı hava ile $12.1 \mathrm{~K}$ olduğu deneysel olarak tespit edilmiştir. Pirinç malzemeden üretilmiş beş orfisli nozul ile hava ve oksijen gazının 7.0 bar giriş basıncında $\Delta \mathrm{T}_{\mathrm{RHVT}}$ değerleri sırasıyla $60 \mathrm{~K}, 70.2 \mathrm{~K}$ olduğu belirlenmiştir (Şekil 11, 12). Öte yandan polyamid plastik malzemeden üretilmiş üç orfisli nozul ile oksijen ve azot gazının 2.0 bar giriş basıncında $\Delta \mathrm{T}_{\mathrm{RHVT}}$ değerleri sırasıyla $20.1 \mathrm{~K}, 25.7 \mathrm{~K}$ olduğu tespit edilmiştir (Şekil 12, 13).

\section{SONUCLAR VE ÖNERILER}

Yapılan deney sonuçlarına göre, RHVT'den elde edilen en yüksek $T_{\text {soğ ve en düşük }} T_{\text {sıc }}$ sıcaklıkları, kullanılan basınçlı akışkana göre sıralaması hava, oksijen azot gazı olduğu deneysel olarak belirlenmiştir. En düşük soğuk akışkan çıkış sıcaklığı azot gazı ile elde edilmiştir. Giriş basıncı arttırıldıkça, $\mathrm{T}_{\text {soğ }}$ (hava, oksijen ve azot) sıcaklığı azalırken, $\mathrm{T}_{\text {sic }}$ ve $\Delta \mathrm{T}_{\mathrm{RHVT}}$ değerleri ise artmıştır. Oksijen ve azot gazı ile yapılan deneylerde paralel bağlı RHVT'den çıkan $\mathrm{T}_{\text {sic }}, \mathrm{T}_{\text {soğ ve }} \Delta \mathrm{T}_{\mathrm{RHVT}}$ değerleri birbiri ile karşılaştıııldığında, azot gazının performansının oksijene göre daha yüksek olduğu deneysel olarak tespit edilmiştir. Ayrıca yapılan çalışma metal olan pirinç malzemesi yapılan nozulun $T_{\text {sıc }}, T_{\text {soğ }}$ ve $\Delta \mathrm{T}_{\text {RHVT }}$ değerleri plastik olan Polyamid nozula göre daha yüksek olduğu deneysel olarak tespit edilmiştir. Deney sonuçları bir bütün olarak incelendiğinde nozulun orfis sayısı ve giriş basıncı arttıkça paralel bağlı olan RHVT'nin performansının arttığı deneysel olarak tespit edilmiştir. RHVT giriş basıncı artıkça $\mathrm{T}_{\text {sıc }}, \mathrm{T}_{\text {soğ }}$ ve $\Delta \mathrm{T}_{\mathrm{RHVT}}$ performansı artacağı ön görülmektedir. Ayrıca Hava içinde bulunan karbondioksit ve argon gazı ile deney yapıldığında RHVT performansının daha yüksek olacağı düşünülmektedir. Değişik nozul malzemeleri, orfis sayısı ve farklı geometrik yapı ile yapılabilecek diğer çalışmalar için literatür olacağı düşünülmektedir. 


\section{KAYNAKLAR}

[1] G. Xiangji, Z. Bo, L. Bo ve X. Xiang, "A Critical Review On The Flow Structure Studies Of Ranque-Hilsch Vortex Tubes," International Journal of Refrigeration, c. 104, ss. 51-64, 2019.

[2] V. Kırmac1, "Seri ve Paralel Bağlı Karşıt Akışl1 Ranque-Hilsch Vorteks Tüpün Isıtma-Soğutma Performansının Karşılaştırılması," Gazi Üniversitesi Fen Bilimleri Dergisi Part C: Tasarım ve Teknoloji, c. 5, s. 4, ss. 159-168, 2017.

[3] K. Dincer, Ş. Başkaya, İ. Üçgül ve B.Z. Uysal, "Giriş ve Çıkış Kütlesel Debilerinin Bir Vorteks Tüpün Performansına Etkisinin Deneysel İncelenmesi," 14. Ulusal Isı Bilimi ve Tekniği Kongresi Bildiri Kitabl, Isparta, Türkiye, 2003, ss. 13-18.

[4] Z. Bo ve G. Xiangji, "Prospective Applications Of Ranque-Hilsch Vortex Tubes To Sustainable Energy Utilization And Energy Efficiency Improvement With Energy And Mass Separation," Renewable and Sustainable Energy Reviews, c. 89, ss. 135-150, 2018.

[5] Y. Xue, M. Arjomandi ve R. Kelso, "Energy Analysis Within A Vortex Tube," Experimental Thermal and Fluid Science, c. 52, ss. 139-145, 2014.

[6] R. Balmer, "Pressure Driven Ranque-Hilsch Temperature Seperation in Liquids," Journal of Fluids Engineering-Transfer of Asme, c. 110, s. 2, ss. 161-164, 1988.

[7] V. Kurmac1, "Experimental Investigation of Cooling -Heating Performance of Counter Flow Ranque-Hilsch Vortex Tubes Having Different Length Diameter Ratio," Cumhuriyet Science Journal, c. 38 , s. 4, ss. 813-821, 2017.

[8] A.E. Gürel, Ü. Ağbulut, A. Ergün ve İ. Ceylan, "Environmental and Economic Assessment Of A Low Energy Consumption Household Refrigerator", Engineering Science and Technology, an International Journal, In Press, https://doi.org/10.1016/j.jestch.2019.06.003.

[9] H. Kaya, F. Günver, O. Uluer ve V. Kırmac1, "Experimental Study About Performance Analysis Of Parallel Connected Ranque-Hilsch Counter Flow Vortex Tubes With Different Nozzle Numbers And Materials," Journal of Heat Transfer-Transactions of The Asme, c. 140, s. 11, ss. 1-8, 2018.

[10] A.E. Özgür, "Vorteks Tüplerin Çalışma Kriterlerine Etki Eden Faktörlerin ve Endüstrideki Kullanım Alanlarının Tespiti," Yüksek lisans tezi, Fen Bilimleri Enstitüsü, Süleyman Demirel Üniversitesi, Isparta, Türkiye, 2001, ss. 70.

[11] W. Fröhlıngsdorf ve H. Unger, "Numerical Investigations of Compressible Flow and the Eneryg Seperation in the Ranque-Hilsch Vortex Tube," International Journal of Heat and Mass Transfer, c. 42, ss. 415-422, 1999.

[12] V. Kırmacı ve H. Kaya, "Effects Of Working Fluid, Nozzle Number, Nozzle Material And Connection Type On Thermal Performance Of A Ranque-Hilsch Vortex Tube: A Review," International Journal of Refrigeration, c. 91, ss. 254-266, 2018.

[13] H. Kaya, F. Günver ve V. Kırmac1, "Experimental Investigation Of Thermal Performance Of Parallel Connected Vortex Tubes With Various Nozzle Materials," Applied Thermal Engineering, c. 136, ss. 287-292, 2018.

[14] V. Kırmac1, H. Kaya ve İ. Cebeci, "An Experimental And Exergy Analysis Of A Thermal Performance Of A Counter Flow Ranque-Hilsch Vortex Tube With Different Nozzle Materials," International Journal of Refrigeration, c. 85 ss. 240-254, 2018. 
[15] K. Dinçer, Y. Y1lmaz, A. Berber ve S. Baskaya, "Experimental Investigation Of Performance Of Hot Cascade Type Ranque-Hilsch Vortex Tube And Exergy Analysis," International Journal of Refrigeration, c. 34, ss. 1117-1124, 2011.

[16] F. Günver, "Paralel Bağl1 Karşıt Akışlı Ranque-Hılsch Vorteks Tüpün Enerji-Ekserji Analizlerinin Deneysel Olarak İncelenmesi," Yüksek lisans tezi, Fen Bilimleri Enstitüsü, Bartın Üniversitesi, Bartın, Türkiye, 2018, ss. 57.

[17] N. Li, G. Jiang, L. Fu, L. Tang ve G. Chen, "Experimental Study Of The Impacts Of Cold Mass Fraction On Internal Parameters Of A Vortex Tube," International Journal of Refrigeration, c. 104, ss. 151-160, 2019.

[18] A. Khait, A. Noskov, V. Alekhin ve V. Bianco, "Analysis Of The Local Entropy Generation In A Double-Circuit Vortex Tube,” Applied Thermal Engineering, c. 130, ss. 1391-1403, 2018.

[19] K. Dinçer ve S. Başkaya "Ekserji Analiz Metoduyla Karşıt Akışlı Ranque Hilsch Vorteks Tüpün Tapa Açısının Ekserji Verimliliğine Etkisinin Değerlendirilmesi, Gazi Üniversitesi Mühendislik Mimarlık Fakültesi Dergisi, c. 24, s.3, ss. 533-538, 2009.

[20] G. Önal ve K. Dinçer, "Experimental Study Of Performance Of A Counter Flow Ranque-Hilsch Vortex Tube With Inner Threaded Body," International Scholarly and Scientific Research \& Innovation, c. 7, s. 8, ss. 1706-1708, 2013.

[21] H. Kaya, O. Uluer, E. Kocaoğlu ve V. Kırmacı "Experimental Analysis Of Cooling And Heating Performance Of Serial And Parallel Connected Counter-Flow Ranquee-Hilsch Vortex Tube Systems Using Carbon Dioxide As A Working Fluid," International Journal of Refrigeration, c. 106, ss. 297307, 2019.

[22] J. Yun, Y. Kim ve S. Yu, "Feasibility Study of Carbon Dioxide Separation from Gas Mixture by Vortex Tube," International Journal of Heat Mass Transfer, c. 126, ss. 353-361, 2018.

[23] M. Attalla, H. Ahmed, M.S. Ahmed ve A.A. El-Wafa, "Experimental Investigation for Thermal Performance of Series and Parallel Ranque-Hilsch Vortex Tube Systems," Applied Thermal Engineering, c. 123, ss. 327-339, 2017.

[24] H.R. Thakare and A.D. Parekh, "Experimental Investigation \& CFD Analysis of Ranque-Hilsch Vortex Tube," Energy, c. 133, ss. 284-298, 2017.

[25] V. Kırmac1, O. Uluer ve K. Dincer, "Exergy Analysis And Performance Of A Counter Flow Vortex Tube: An Experimental Investigation With Various Nozzle Numbers At Different Inlet Pressures Of Air, Oxygen, Nitrogen And Argon," Journal of Heat Transfer-Transactions of The Asme, c. 12, ss. 121701-121701, 2010.

[26] S. Subudhi ve M. Sen, "Review Of Ranque-Hilsch Vortex Tube Experiments Using Air," Renewable \& Sustainable Energy Reviews, c. 52, ss. 172-178, 2015. 